\title{
Survival of dental implants and occurrence of osteoradionecrosis in irradiated head and neck cancer patients: a systematic review and meta-analysis
}

\author{
Daniel Jan Toneatti ${ }^{1}$ D $\cdot$ Ronny Roger Graf $^{1} \mathbb{D} \cdot$ John-Patrik Burkhard $^{1} \mathbb{D} \cdot$ Benoît Schaller $^{1}$ (D)
}

Received: 21 January 2021 / Accepted: 29 June 2021 / Published online: 16 August 2021

(C) The Author(s) 2021, corrected publication 2022

\begin{abstract}
Objectives This systematic review assesses dental implant survival, calculates the incidence rate of osteoradionecrosis, and evaluates risk factors in irradiated head and neck cancer patients.

Materials and methods Various databases (e.g., Medline/Embase using Ovid) and gray literature platforms were searched using a combination of keywords and subject headings. When appropriate, meta-analysis was carried out using a random effects model. Otherwise, pooled analysis was applied.

Results A total of 425 of the 660 included patients received radiotherapy. In total, 2602 dental implants were placed, and 1637 were placed in irradiated patients. Implant survival after an average follow-up of 37.7 months was $97 \%$ (5\% confidence interval, CI 95.2\%, 95\% CI 98.3\%) in nonirradiated patients and 91.9\% (5\% CI 87.7\%, 95\% CI: 95.3\%) after an average follow-up of 39.8 months in irradiated patients. Osteoradionecrosis occurred in 11 cases, leading to an incidence of $3 \%$ (5\% CI 1.6\%, 95\% CI 4.9\%). The main factors impacting implant survival were radiation and grafting status, while factors influencing osteoradionecrosis could not be determined using meta-analysis.

Conclusion Our data show that implant survival in irradiated patients is lower than in nonirradiated patients, and osteoradionecrosis is-while rare-a serious complication that any OMF surgeon should be prepared for. The key to success could be a standardized patient selection and therapy to improve the standard of care, reduce risks and shorten treatment time.

Clinical relevance Our analysis provides further evidence that implant placement is a feasible treatment option in irradiated head and neck cancer patients with diminished oral function and good long-term cancer prognosis.
\end{abstract}

Keywords Radiotherapy · Dental implants · Osteoradionecrosis $\cdot$ Mandibular reconstruction $\cdot$ Bone grafting $\cdot$ Hyperbaric oxygenation

\section{Introduction}

Oral and pharyngeal malignancies are the sixth most common cancers worldwide and comprise approximately $3.6 \%$ of all cancers $[1,2]$. Approximately $90 \%$ of these malignancies are squamous cell carcinomas, which typically occur in males over 50 years old [3]. Tobacco and alcohol consumption alone increase the risk for oral squamous cell carcinoma by factors of 3.43 and 2.54 , respectively $[4,5]$. Combining

Benoît Schaller

benoit.schaller@insel.ch

1 Department of Cranio-Maxillofacial Surgery, Inselspital, Bern University Hospital, University of Bern,

CH-3010 Bern, Switzerland these two shows a more than multiplicative synergistic risk increase [6]. Oral squamous cell carcinoma is also often associated with poor oral hygiene [7].

Patients with oral and pharyngeal cancer treated with ablative surgery and adjuvant radiotherapy have a 5-year survival rate of $51.3 \%$. Unfortunately, this rate has been stable over the last decades and cannot be significantly improved because detection is still delayed [8].

Cancer treatment results in significant morbidity and oral rehabilitation that is often unsatisfactory for patients [9]. Their main communication feature-their face-has changed. Their speech, mastication, swallowing, and breathing may be severely compromised, and their oral comfort, facial expression, and esthetics may be impacted. Consequently, their psychological condition, social life, and quality of life in general might be diminished [10]. 
Some of these challenges could be resolved by using dental implants during oral rehabilitation. However, many clinicians view implants as contraindicated and are currently reluctant to use them in irradiated head and neck cancer patients [11]. Their main concerns are altered anatomy and impaired wound healing, which make placing implants in the correct prosthodontic position difficult, and complications such as failed osseointegration, soft tissue hyperplasia, and osteoradionecrosis (ORN) more probable.

\section{Objective of this review}

The main goal of this systematic review was to study the occurrence of osteoradionecrosis after placing dental implants in irradiated jaws by calculating an incidence rate and isolating risk factors. At the same time, the extracted data were used to determine a survival rate for dental implants in irradiated patients.

The target questions were "What is the survival rate of dental implants in irradiated patients?", "How common is ORN after dental implant surgery in irradiated patients?" and "Which factors influence implant survival and development of ORN in irradiated head and neck cancer patients?".

Answering those questions is clinically significant as they would allow the selection of patients with a low risk and the application of beneficial preventive methods in patients with a high risk for implant failure and ORN.

\section{Materials and methods}

This review followed the Preferred Reporting Items for Systematic reviews and Meta-Analyses (PRISMA) and the Meta-Analysis Of Observational Studies in Epidemiology (MOOSE) statement guidelines [12, 13]. Additionally, the Cochrane handbook was used [14].

The full study protocol can be assessed on the International Prospective Register of Systematic Reviews (PROSPERO, identification code: CRD42018107153) or using Mendeley Data [15].

\section{Search strategy}

Initially, a preliminary search on Google Scholar, Microsoft Academic, and PROSPERO was performed to identify core articles and to estimate the need for a systematic review.

Because the examiners concluded that there was a lack of evidence, an electronic search was set up. The universal "Patient, Intervention, Control, Outcome" (PICO) and the more specific "Condition, Context, Population" (CoCoPop) method were applied and used as a framework to develop a search strategy in which keywords and subject headings were combined $[16,17]$.
The electronic search strategy was reviewed by the coexaminers using the Peer Review of Electronic Search Strategies (PRESS) checklist [18].

Electronic searches (up until 05.04.2021) were performed on multiple databases, including Ovid (MEDLINE, Embase), PubMed, CENTRAL, CINAHL, PsycINFO, Scopus, and Web of Science. Databases for gray literature were selected using the Canadian Agency for Drugs and Technologies in Health (CADTH) "Grey matters checklist" and the guidelines of the University of Bern $[19,20]$. To limit the overlap of results between Ovid and PubMed, a filter proposed by the CADTH was applied [21]. Otherwise, no filters or limitations were utilized.

Additionally, a manual search was carried out using core articles and reviews, which came up during the search process.

The PICO and CoCoPop frameworks and the complete search strategy used on the Ovid database can be found in Mendeley Data [15].

\section{Eligibility criteria}

Eligibility criteria were created following the approach described by Munn et al. (2015) and the Cochrane handbook $[14,22]$. The PICO and CoCoPop framework served as a foundation for creating those inclusion/exclusion criteria.

An article was included if its full text was available in English, French, or German. Published and gray literature were regarded equally. The studies had to contain clinical data, either obtained in an observational or interventional study design. Case reports, reviews, guidelines, or data collected in a survey were excluded.

The study sample had to consist of a minimum of 5 patients, who each underwent radiotherapy in the head and neck region (affecting mandible, maxilla, or both) and had an edentulous area that needed oral rehabilitation using at least one dental implant. Studies containing data on nonorally used facial implants were excluded.

Articles including patients undergoing comedications or cointerventions (e.g., additional chemotherapy, reconstructive surgery, hyperbaric oxygen therapy) were allowed, and those procedures were specifically recorded.

Eligible studies had to report on essential data (number of patients, number of implants placed, number of failed implants, reason for implant failures, minimum duration of follow-up), and if subgroups (e.g., nonirradiated control) were present, the division had to be reproducible and essential data had to be assignable to each group individually.

If a case of osteoradionecrosis was diagnosed, there needed to be a topological and chronological correlation between the placed implant and the occurrence of ORN.

The minimum follow-up for individual subjects was at least 3 months and for groups at least 6 months after 
implantation. Studies with unclear minimum follow-up durations were excluded.

\section{Study selection}

The obtained search results were exported to Mendeley (Version 1.19.4). First, only the study title and abstract were considered for study selection. Potentially included studies were further assessed using their full text. The eligibility criteria determined which studies were included in this review (for the title/abstract and full text analysis), and for every study, the reason for exclusion was recorded in Mendeley.

The study selection process can be tracked in detail in the PRISMA flow diagram in Fig. 1.
This procedure was done by a single individual. However, doubtful cases and the included studies were all discussed with the co-examiners.

\section{Data extraction}

The following data extraction was performed in Microsoft $₫$ Excel® using the full text of the included studies. If possible, subgroups were separated, and missing data for those subgroups were calculated if a detailed patient demographics or implant survival table was available.
Fig. 1 Adapted PRISMA flowdiagram. A single asterisk $\left(^{*}\right)$ indicates application of a filter proposed by the CADTH
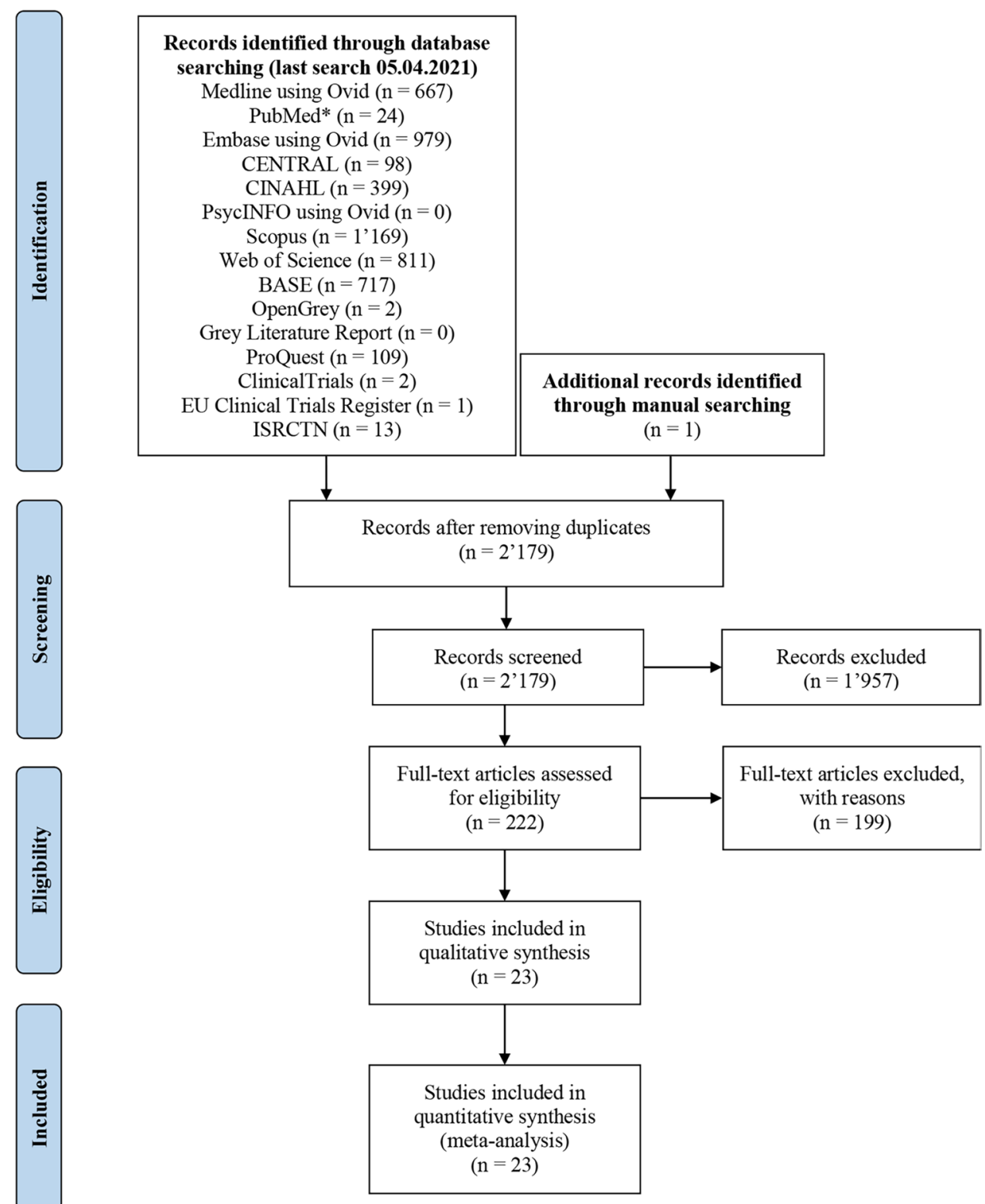


\section{Quality assessment}

The limitations of each article were assessed using a checklist from The Joanna Briggs Institute that was appropriate for the respective study design [23].

\section{Statistical analysis}

The descriptive statistics were performed using the builtin Microsoft ${ }^{\circledR}$ Excel ${ }^{\circledR}$ tools. For meta-analysis, a random effects model was introduced. Incidence data were handled as proposed by Barendregt et al. (2013) using a double arcsine transformation in MetaXL (Version 5.3) [24, 25]. Subgroups were analyzed in RevMan (Version 5.4) [26]. If meta-analysis was not possible, pooled analysis was used.

It is important to point out that no article was excluded during analysis due to its results. However, some studies could not be included in the calculation due to the lack of specific data (e.g., average age, sex distribution) or due to mixed subgroups (e.g., occurrence of osteoradionecrosis in grafted compared to nongrafted bone).

Other studies labeled implants in deceased patients or in patients with tumor recurrences as failures. The same can be said about implants who were "put to sleep." Since this would lead to false low survival rates, these data were corrected by excluding the implants in question in implant survival analysis and during pooled analysis.

\section{Results}

A summarized table of the extracted data can be found in Tables 1,2, and 3. The full data extraction, a complete quality assessment and the forest and funnel plots corresponding to the results below can be accessed on Mendeley data [15].

In this systematic review, the data of 23 studies, with an average of 28.7 patients each, were extracted. This accumulates to information for approximately 660 patients. Of those, $63 \%$ (416 patients) were male, $31 \%$ (202 patients) were female, and in $6.3 \%$ (42 patients), sex was not specified. The average age was $59.5( \pm 5.4)$ years. A total of 638 patients underwent head and neck cancer treatment, while the other 22 noncancer patients were otherwise surgically reconstructed.

Most patients $(63 \%, 414$ patients) in the included articles suffered from squamous cell carcinoma. A total of 425 $(64.4 \%)$ of the 660 patients were treated with radiotherapy and received an average radiation dose of $55.8( \pm 7.6)$ Gray. Chemotherapy was given to $12.4 \%$ ( 82 patients).

In total, 2602 dental implants were placed, 1637 (62.9\%) of which were in the irradiated subgroup. This leads to an average of 3.9 dental implants per patient. The most frequently used location for dental implants was the mandible
(1995 implants or 76.7\%). The maxilla was used for 203 implants (7.8\%), and in 404 implants (15.5\%), the implant location remained unclear. In 3 studies (68 implants in 27 irradiated patients), implants were placed primarily, while in the other 20 reports (1702 in at least 416 irradiated patients), secondary implant placement was used. In the study of Watzinger et al. (1996), a subgroup with an unknown size underwent 52 partly immediate, partly delayed implantations.

The average interval between primarily placed implants and radiotherapy was 6 weeks, whereas in the case of secondary implant surgery, a median waiting period of 30.7 months was respected. During implantation, antibiotics were given to $42.1 \%$ (179 irradiated patients), and hyperbaric oxygen therapy was used in $15.1 \%$ of irradiated patients (64 irradiated patients).

After an average follow-up of 37.7 months, 97\% (5\% confidence interval; CI 95.2\%; 95\% CI 98.3\%) of implants were still in situ in the nonirradiated control group, whereas the irradiated subgroup had a survival rate of $91.9 \%$ (5\% CI 87.7\%; 95\% CI; 95.3\%) after an average 39.8-month follow-up.

Meta-analysis for implant survival confirmed that radiotherapy is a risk factor for implant survival (OR 2.68 resp. 3.08). However, pooled analysis showed that an average radiation dose above 60 Gray did not seem to negatively influence implant outcome ( $p$-value 0.89 ). A waiting period of more than 12 months between irradiation and implantation seems to be beneficial (OR 3.2), and the application of hyperbaric oxygen before implant placement had a nonsignificant impact ( $p$-value 0.17 resp. 0.98 ) in pooled analysis.

Placing implants in grafted bone showed a significantly worse prognosis only in pooled analysis of irradiated patients (OR 2.67). In nonirradiated patients, implants inserted in native and grafted bone showed a comparable clinical outcome ( $p$-value 0.29 resp. 0.93 ).

Pooled analysis also suggests that primary/immediate implant surgery increases the risk of implant failure compared to using a secondary/delayed procedure (OR 3.2). No difference between submerged and nonsubmerged surgical approaches ( $p$-value 0.19 ) in irradiated patients was noted. Loading implants before 6 months seemed to increase the number of implants in situ (OR 0.56).

Osteoradionecrosis occurred in 11 cases, leading to an incidence of $3 \%$ (5\% CI 1.6\%; 95\% CI 4.9\%). Due to this complication, an average of 2.5 implants were lost. Two of the 11 cases occurred after implant failure. One additional event was unrelated to the implant site and therefore not included in the calculations.

Pooled analysis showed that the risk for ORN was unrelated to the radiation dose surpassing 60 Gray ( $p$-value 0.37 ) or if a waiting period of 12 months between radiotherapy and implantation was respected ( $p$-value 0.1). Patients undergoing hyperbaric oxygen therapy had an increased risk 


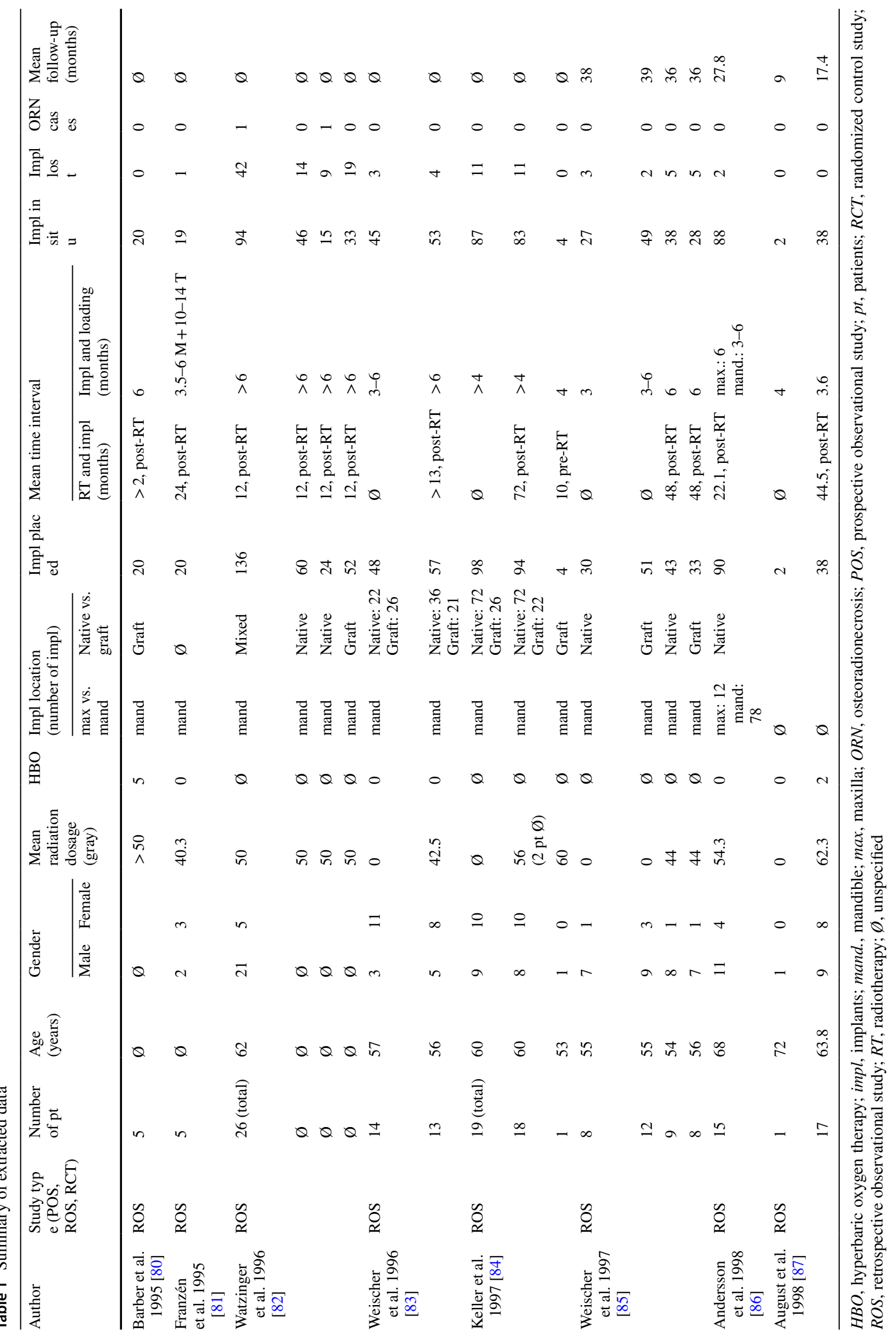




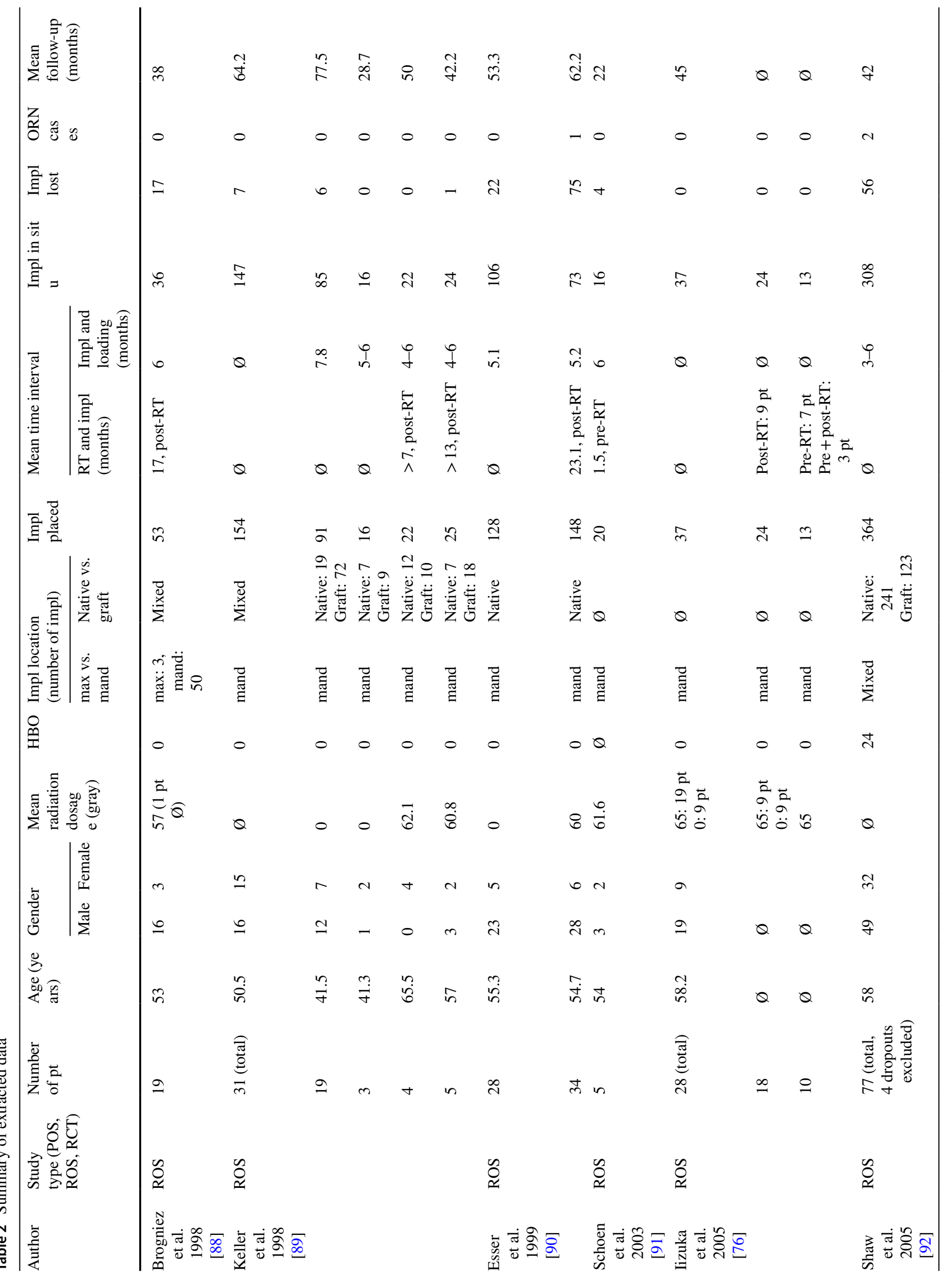


for osteoradionecrosis (OR 5.95). Implant surgery involving grafted bone demonstrated a higher number of cases compared to native bone (OR 6.8). Immediate/primary implantation appeared to increase risk (OR 7.3) in this group of patients, while no difference between submerged and nonsubmerged approaches could be detected ( $p$-value 0.99). Implant loading protocols (earlier or later than 6 months after implantation) also did not seem to influence ORN occurrence ( $p$ value 0.37).

\section{Discussion}

The main objective of this systematic review was to investigate the benefits and risks of dental implantation in irradiated head and neck cancer patients and to study the occurrence of osteoradionecrosis after this surgical procedure.

Three focus questions were developed: "What is the survival rate of dental implants in irradiated patients?", "How common is osteoradionecrosis after dental implant surgery in irradiated patients?" and "Which factors influence implant survival and development of osteoradionecrosis in irradiated head and neck cancer patients?".

The mostly male patients $(63 \%, 416$ patients) and those with median age of 59.5 years were at high risk for oral malignancies. A multicenter study by Dhanuthai et al. (2017) including 6151 oral cancer patients showed a gender distribution of $68.9 \%$ males and a mean age of 58.37 years [27]. Tandon et al. (2017) published comparable results in their 10-year retrospective study (age peak above 50 years, $59.01 \%$ males) [3]. The higher prevalence in men can be explained by their more common risk behaviors.

Sixty-three percent (414 patients) in this systematic review suffered from oral squamous cell carcinoma. This is lower than $90 \%$, which could be expected for cancers of the oral cavity [3]. This difference could be caused by the high number of patients $(27.4 \%, 181$ patients) in which the type of pathology was not clearly specified.

\section{Implant survival}

The calculated implant survival during the average 37.7month follow-up in the nonirradiated control group was high (97\%) but still considerably lower than the 10-year survival rate reported by Buser et al. in 2012 (98.8\%) [28]. However, the control group mostly consisted of head and neck cancer patients in which ablative surgery was necessary. This makes altered-sometimes even reconstructed-anatomy common and therefore proper implant positioning, successful osseointegration, and complication-free soft tissue healing even without radiotherapy harder to achieve. Suboptimal implant positioning could lead to occlusal overloading, while soft 


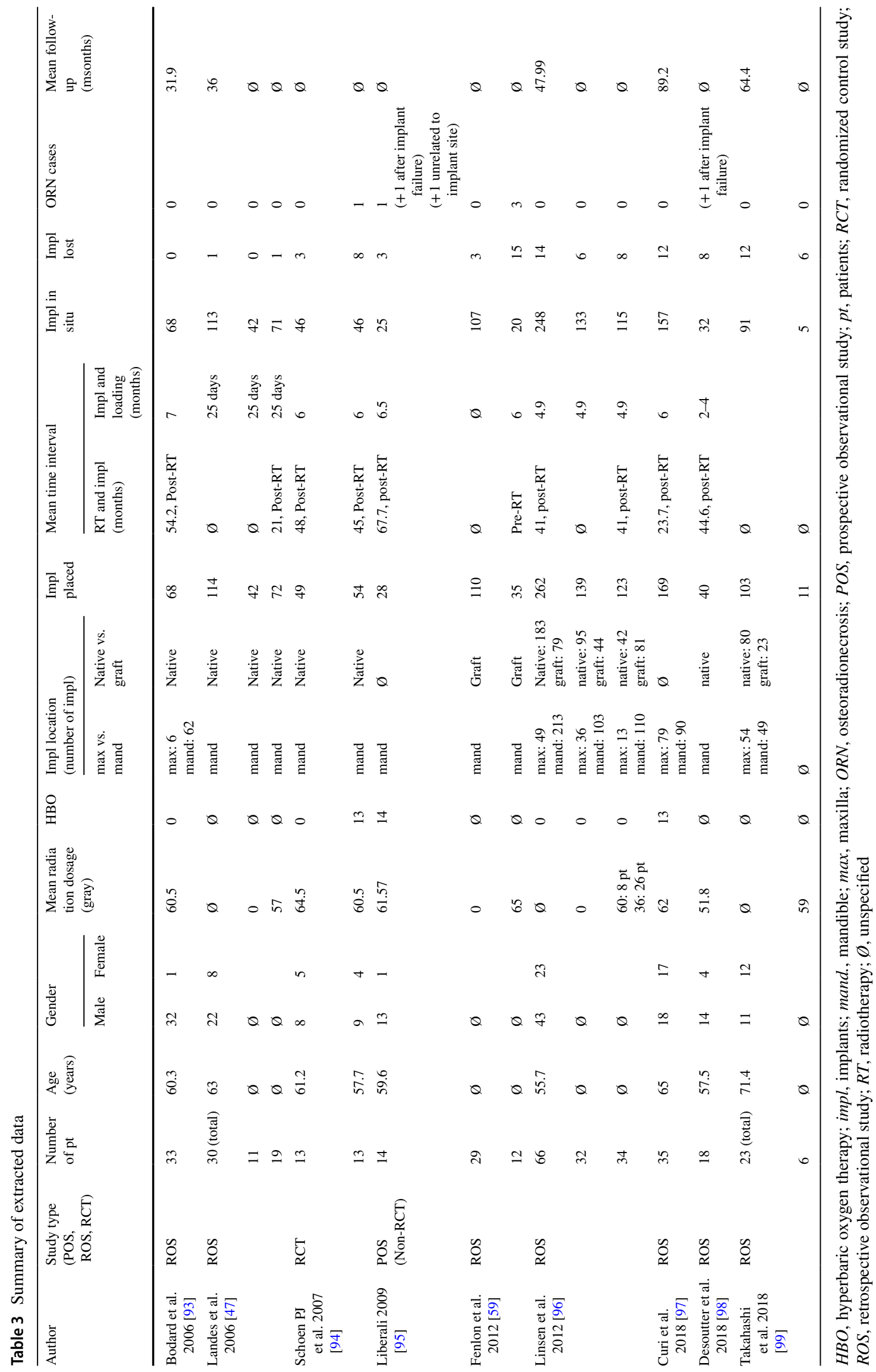


tissue hyperplasia could make plaque control more difficult. Patients affected by oral carcinomas often have a history of alcohol and/or tobacco abuse and show worse oral hygiene $[4,5,7]$. Additionally, those patients suffer from increased morbidity, again negatively impacting their capability for sufficient plaque control. In contrast to the Bernese study in which only nonrisk patients were treated with Straumann ${ }^{\circledR}$ SLA® implants (Straumann® Dental Implant System, Straumann Holding AG, Basel, Switzerland) and most implants were placed by a single surgeon, this systematic review-by nature-consists of data in which different implant types and manufacturers were used by various surgeons. All these factors could have negatively impacted implant survival.

In the irradiated group, the implant survival during the average 39.8-month follow-up was lower (91.9\%) than that in the control group. This was expected as those patients have an even higher morbidity (e.g., trismus, fibrinoid soft tissue erosions or xerostomia), impacting their capability for proper oral hygiene. Furthermore, irradiated tissue shows worse wound healing, and a risk for the development of osteoradionecrosis exists. These survival rates are in agreement with the one obtained by Smith Nobrega et al. (2016) at $84.3 \%$ after up to 192 months [29].

Excluding patient death or tumor recurrence, most implants in the control and irradiated groups were lost due to failed osseointegration (42.9\%), followed by peri-implantitis (28.6\%). Other reasons included pathological bone fractures, occlusal overloading, excessive soft tissue hyperplasia, soft tissue necrosis, or osteoradionecrosis. Presumably, occlusal overloading is caused by implant malposition as bite force is on average 50\% lower in resected jaws than in healthy controls [30].

The lower implant survival in irradiated patients could be reproduced during meta-analysis. In contrast to other authors-who established an increased risk for implant failure if the applied dosage surpassed 50-60 Gray-we were unable to prove the existence of a radiation dose-failure relationship [31-33].

Introducing subgroups depending on the patient grafting status lowered the heterogeneity of the sample. Further pooled analysis showed that placing implants in grafted bone seems to negatively influence implant survival (OR 2.67). In the meta-analysis of Schiegnitz et al. (2014), an odds ratio of 1.82 for implant placement in grafted bone was calculated [34]. Shugaa-Addin et al. (2016) also showed a lower survival of implants in grafted than native bone. In particular, nonvascularized bone grafts seem to be associated with lower implant survival. According to this study, bone grafts show a lower bone density, volume, vascularization, and higher resorption [35].

Our pooled data suggest that placing implants during initial surgery increases the risk for implant failure (OR 3.2). A recent review by Alberga et al. (2020) came to the opposite conclusion [36]. As shown by Schoen et al. (2008), neither immediate nor delayed implantation is ideal [37]. Hence, it could be useful to adapt the approach to the individual clinical situation and the available resources.

A relevant impact on implant survival depending on the interval between radiotherapy and implant placement could also be detected in pooled analysis. In our study, placing implants during the first 12 months after irradiation increased the risk for implant failure (OR 3.2). Claudy et al. (2015), who showed similar results and provided data, showed that placement of dental implants between 6 and 12 months after radiotherapy was associated with a $34 \%$ higher risk of failure [38]. Some argue that bone recovery occurs 6-12 months after radiotherapy, which could improve the patient's regeneration capacity [39]. This is verified by a higher necessary removal torque [40]. In contrast, $\mathrm{Chr}$ canovic et al. (2016) were unable to show a significant improvement after a waiting period of more than 1 year [41]. Granström et al. (2006) proposed keeping the interval rather short because over time ( $>10$ years), progressive endarteritis could reduce the healing potential [42]. This leads to the conclusion that time has two antagonistic effects on irradiated tissue recovery. There is a short-term positive cellular effect improving the bone healing capacity and a long-term negative effect on vascularity [31]. Another aspect to consider is tumor recurrence, which often occurs within the first year. Therefore, while waiting for 12 months could lead to some benefits-such as better tissue healing and increased tumor control - additional surgical delay might not be indicated, and a patient's risk for complications might even increase.

If a significant difference in implant survival between the maxilla and mandible or anterior and posterior implant position exists, could not be analyzed due to insufficient data. However, in 1996, Eckert et al. already proved implantation in the mandible to be more successful [43]. Systematic reviews by Chambrone et al. (2013) and Colella et al. (2007) on dental implants in irradiated patients were able to verify those results by showing a higher survival rate in the mandible $[44,45]$. This could be caused by the higher amount of dense, compact bone, which leads to better primary stability. Data from Lee et al. (2012) suggest that the anterior mandible is often spared from high radiation doses during radiotherapy, which could benefit anterior implant placement [46].

In the included study by Landes et al. (2006), implants were placed in a one-stage procedure, and prosthodontic rehabilitation took place according to early-loading principles [47]. Although those nonsubmerged implants did not show a reduced survival rate, further studies-preferably with a prospective design - are needed to endorse this approach. However, according to our data, the waiting 
period of 6 months as endorsed by many does not seem to be essential in providing optimal care.

A systematic review by Shah et al. (2017) on hyperbaric oxygen therapy (HBO) showed a reduced risk for implant failure (reducing the risk by a factor of 1.2), while a Cochrane review by Esposito et al. (2013) did not recommend its use due to the lack of randomized controlled trials $[48,49]$. A recent randomized controlled trial by Shaw et al. (2019) supports our data that HBO does not seem to significantly improve implant survival [50].

Other potential risk factors for implant loss in irradiated jaws, such as age, smoking status, chemotherapy, or use of antibiotics, could not be isolated in the present study due to insufficient reporting. Moy et al.'s (2005) data indicate a higher risk for implant failure in above 60 -year-olds, smokers, or patients suffering from diabetes. Neither Moy et al. (2005) nor Kovács (2001) demonstrated reduced implant survival after chemotherapy [51, 52]. Unfortunately, there is no evidence on the effectiveness of prescribing antibiotics before, during, or after implant surgery in irradiated patients [53]. Furthermore, we want to emphasize the importance of proper oral hygiene, adequate prosthetic rehabilitation and frequent follow-up appointments.

It is also notable that implant loss in most cases does not lead to complete rehabilitation failure [54].

\section{Osteoradionecrosis}

In their 30-year retrospective review, Reuther et al. (2003) reported an overall osteoradionecrosis incidence rate of $8.2 \%$ [55]. After tooth extraction, Nabil et al. (2011) described a $7 \%$ incidence rate if no preventive method was used, while a lower incidence rate could be observed after applying hyperbaric oxygen (4\%) or antibiotics (6\%) [56].

Few studies estimate the incidence of ORN after implant surgery. Wagner et al. (1998) stated an incidence of 1.6\% (1 case, 63 irradiated patients), and Keller et al.'s (1997) review proposed an incidence of $1.8 \%$ ( 3 cases, 170 irradiated patients) [57, 58]. In our study, osteoradionecrosis occurred in 11 out of 425 irradiated patients after implantation, resulting in an incidence rate of $3 \%$. While our proposed incidence rate is higher than those previously published, those values are still inside our calculated confidence intervals (5\% CI $1.6 \%$; $95 \%$ CI $4.9 \%$ ). A possible explanation for this difference is the uncommonness of osteoradionecrosis. Hence, inclusion of a single study with a high number of cases could impact the estimated incidence. In our study, Fenlon et al. (2012) provided 3 out of 11 ORN cases [59]. The small sample size of the previously published articles could also play a role.

Because many of the physiological aspects of irradiated bone and the molecular factors that lead to osteoradionecrosis remain unclear, isolating risk factors and finding efficient preventive methods is difficult. The rare and unpredictable appearance of osteoradionecrosis further aggravates this problem. The following subgroup analysis should thus be evaluated carefully.

Our data do not support the often-proclaimed dosedependent osteoradionecrosis risk increase or any threshold values for the occurrence of osteoradionecrosis [60]. Nevertheless, lower radiation doses might preserve the body from excessive damage, therefore reducing endarteritis and leading to a lesser extent of fragile hypovascular, hypoxic, and hypocellular tissue. Sparing tissue from radiation and placing implants in areas that were exposed to lower radiation doses should be enforced whenever possible.

While we were unable to track the specific location in which ORN appeared, Dumoulin et al.'s (2021) analysis of 32 cases shows that ORN most often occurs in the body of the mandible. The ramus or symphysis was affected less frequently, whereas no case in the maxilla was observed [61].

Analyzing pooled data, implants placed during reconstructive surgery and in grafted bone showed a higher risk for ORN. However, both analyses were severely influenced by the higher number of cases in the article by Fenlon et al. (2012) [59].

In general, using more minimally invasive approaches during secondary implant placement—reducing additional trauma - should be aimed towards to decrease risk. Future prospective trials researching the impact of ideally flapless computer-aided implant surgery (CAIS) on the incidence of osteoradionecrosis could be interesting.

Additional risk factors for ORN that could be isolated by Dumoulin et al. (2021) or Owosho et al. (2017) are smoking, alcohol abuse, diabetes, and poor periodontal status [61, 62].

Shaw et al.'s (2019) randomized controlled trial provided evidence that $\mathrm{HBO}$ does not reduce the risk for ORN after oral surgery, which is consistent with our analysis [50].

Pentoxifylline and vitamin E (alpha-tocopherol) have been shown to reduce a patient's risk of developing osteoradionecrosis after dental extraction [63]. A prophylactic application before implant placement could also be conceivable. There are various other current research projects trying to improve implant osseointegration or soft tissue healing, such as using low-level laser therapy (LLT), the application of bone morphogenetic protein 2 (BMP2), platelet-rich plasma (PRP) treatment, the use of stem cells or optimizing the features of the inserted implants [64-69]. Implementing promising approaches could help to advance implant surgery and reduce the incidence of osteoradionecrosis.

As seen in our study, not only implant surgery but also implant failure or even implant manipulation-such as periimplantitis treatment leading to soft tissue trauma-could cause osteoradionecrosis. Thus, handling those patients carefully, improving implant prognosis and optimal prosthodontic rehabilitation are integral parts of ORN prevention. 
Recent publications argue that dental extractions or implantations might not be the cause of ORN but rather accelerate the clinical manifestation of necrotic bone tissue $[50,70,71]$. If this would turn out to be true, reliable screening methods for the preclinical stages of ORN need to be identified and implemented before elective oral surgeries.

\section{Quality of life and workflow}

The goal of placing implants in irradiated head and neck cancer patients is to enable sufficient oral rehabilitation and therefore increase their quality of life while not endangering their survival and staying economically reasonable. However, patients with high morbidity, who would benefit the most from implant surgery, tend to be high-risk patients with a poor long-term prognosis. During the patient selection process, it should be considered if the additional risks, costs, and increase in rehabilitation time are worth the elective surgical procedure to increase the quality of life in high-risk patients with a low prospective 5-year survival. While strict selection is ideal for keeping complication rates low, it also severely limits the number of patients who can benefit from implant surgery.

The percentage of patients who complete treatment $(22-91 \%)$ and the total time needed for it vary harshly between different studies [72]. Treatment drop-out or long duration negatively impacts patient quality of life.

A well-thought-through treatment concept could help to simplify and optimize the selection process and choose ideal candidates for implant placement, simultaneously reducing treatment time and increasing the number of completed rehabilitations $[10,73]$. Criteria for patient selection were defined by Chiapasco et al. (2006), who proposed excluding patients with persisting alcohol or tobacco abuse and poor compliance, whereas good tumor prognosis, sufficient oral hygiene, absence of periodontal disease, or patient request were seen as inclusion criteria [74]. Smolka et al. (2008) evaluated a treatment concept based on the defect classification by Iizuka et al. (2005), in which the number of osteotomies needed to recreate the mandibular contour was the defining factor. In this treatment concept, the mandibular defect size-described by the classification above-dictates the type of prosthodontic rehabilitation. They were able to show a high percentage of successfully completed functional dental reconstructions and had similar results to conventionally planned rehabilitations in terms of implant survival and complication rates [75, 76]. Rouers et al. (2019) proposed an earlier inclusion of the prosthodontist into the treatment process by selecting implant sites before radiation treatment dosimetry [77]. Combining those or similar approaches to standardized workflows could not only potentially impact treatment outcome and the patient's quality of life but also help to generate more comparable data.

\section{Limitations}

As always, the results of a systematic review should be critically analyzed because there are several limitations. There was an inevitable selection bias because there was a single examiner during study selection. To offset this bias, every doubtful case and every study that was included in the final review were discussed with the co-examiners.

Although most studies are published in English, the exclusion of studies based on their language could contribute to a possible selection bias.

Since cancer patients suffer from a low survival rate, implant placement in irradiated patients is not the norm, and the occurrence of osteoradionecrosis is rare. Large patient groups are necessary to gather reliable information. For the same reasons, the number of prospective or randomized controlled trials is extremely low, and most included studies are retrospective. Thus, we deemed it important to evaluate the quality of each study individually by using the most suitable checklist from The Joanna Briggs Institute for each article.

A side effect of the mostly retrospective study designs was the common lack of control groups. Often, true metaanalysis was not possible, and pooled analysis had to be used when taking a closer look at a specific subgroup. This increases the risk of bias and artificially narrows confidence intervals $[78,79]$. There was also a lack of individual data (e.g., on applied radiation dosage), which impeded certain analyses (e.g., radiation dose threshold for implant survival). Furthermore, a relevant difference between the included studies is the definition of implant success or implant survival. Some studies excluded patients who died or had tumor recurrences during the follow-up, while others counted them as successful or saw them as failures. Even if this was accounted for during analysis, the initial data still showed inconsistency.

Additionally, the researched population is quite heterogeneous (e.g., initial diagnosis, defect size, reconstruction method, implant brand and type, prosthesis design, radiation technique, treatment year), and because there are no standardized classification systems in place, comparing individuals in a single clinic - let alone between completely varying settings-is associated with a high risk.

All these factors negatively impact the level of evidence of our systematic review and meta-analysis and show that there is a severe lack of prospective or randomized controlled trials for the oral rehabilitation of head and neck cancer patients. 
Funding Open Access funding provided by Universität Bern.

\section{Declarations}

Conflict of interest The authors declare no conflict of interest.

Open Access This article is licensed under a Creative Commons Attribution 4.0 International License, which permits use, sharing, adaptation, distribution and reproduction in any medium or format, as long as you give appropriate credit to the original author(s) and the source, provide a link to the Creative Commons licence, and indicate if changes were made. The images or other third party material in this article are included in the article's Creative Commons licence, unless indicated otherwise in a credit line to the material. If material is not included in the article's Creative Commons licence and your intended use is not permitted by statutory regulation or exceeds the permitted use, you will need to obtain permission directly from the copyright holder. To view a copy of this licence, visit http://creativecommons.org/licenses/by/4.0/.

\section{References}

1. Warnakulasuriya S (2009) Global epidemiology of oral and oropharyngeal cancer. Oral Oncol 45:309-316. https://doi.org/10. 1016/j.oraloncology.2008.06.002

2. Bray F, Ferlay J, Soerjomataram I et al (2018) Global cancer statistics 2018: GLOBOCAN estimates of incidence and mortality worldwide for 36 cancers in 185 countries. CA Cancer J Clin 68:394-424. https://doi.org/10.3322/caac.21492

3. Tandon P, Dadhich A, Saluja H et al (2017) The prevalence of squamous cell carcinoma in different sites of oral cavity at our Rural Health Care Centre in Loni, Maharashtra - a retrospective 10-year study. Współczesna Onkol 2:178-183. https://doi.org/ $10.5114 /$ wo. 2017.68628

4. Gandini S, Botteri E, Iodice S et al (2008) Tobacco smoking and cancer: a meta-analysis. Int J Cancer 122:155-164. https:// doi.org/10.1002/ijc.23033

5. Turati F, Garavello W, Tramacere I et al (2013) A meta-analysis of alcohol drinking and oral and pharyngeal cancers: results from subgroup analyses. Alcohol Alcohol 48:107-118. https:// doi.org/10.1093/alcalc/ags100

6. Hashibe M, Brennan P, Chuang S et al (2009) Interaction between tobacco and alcohol use and the risk of head and neck cancer: pooled analysis in the International Head and Neck Cancer Epidemiology Consortium. Cancer Epidemiol Biomarkers Prev 18:541-550. https://doi.org/10.1158/1055-9965. EPI-08-0347

7. Oji C, Chukwuneke F (2012) Poor oral hygiene may be the sole cause of oral cancer. J Maxillofac Oral Surg 11:379-383. https://doi.org/10.1007/s12663-012-0359-5

8. Ford PJ, Farah CS (2013) Early detection and diagnosis of oral cancer: strategies for improvement. J Cancer Policy 1:e2-e7. https://doi.org/10.1016/j.jcpo.2013.04.002

9. Komisar A (1990) The functional result of mandibular reconstruction. Laryngoscope 100:364-374. https://doi.org/10.1288/ 00005537-199004000-00007

10. Jacobsen C, Kruse A, Lübbers H-T et al (2014) Is mandibular reconstruction using vascularized fibula flaps and dental implants a reasonable treatment? Clin Implant Dent Relat Res 16:419-428. https://doi.org/10.1111/cid.12004

11. Fischer-Brandies E (1990) Das Risiko enossaler Implantationen nach Radiatio. Quintessenz 5:873-879

12. Hutton B, Salanti G, Caldwell DM et al (2015) The PRISMA Extension statement for reporting of systematic reviews incorporating network meta-analyses of health care interventions: checklist and explanations. Ann Intern Med 162:777. https://doi.org/10.7326/M14-2385

13. Stroup DF, Berlin JA, Morton SC et al (2000) Meta-analysis of observational studies in epidemiology: a proposal for reporting. Meta-analysis Of Observational Studies in Epidemiology (MOOSE) group. JAMA 283:2008-2012. https://doi.org/10. 1001/jama.283.15.2008

14. Higgins JPT, Thomas J, Chandler J, Cumpston M, Li T, Page MJ, Welch VA (editors). Cochrane handbook for systematic reviews of interventions version 6.2 (updated February 2021). Cochrane, 2021. Available from www.training.cochrane.org/handbook.

15. Toneatti DJ, Graf RR, Burkhard J-P, Schaller B (2021) Supplementary data - survival of dental implants and occurrence of osteoradionecrosis in irradiated head and neck cancer patients: a systematic review and meta-analysis. Mendeley Data V1. https://doi.org/10.17632/v8988ft5zm.1

16. Costa Santos CMC da, MattosPimenta CA de, Nobre MRC (2007) The PICO strategy for the research question construction and evidence search. Rev Lat Am Enfermagem 15:508-511. https://doi.org/10.1590/S0104-11692007000300023

17. Munn Z, Stern C, Aromataris E et al (2018) What kind of systematic review should I conduct? A proposed typology and guidance for systematic reviewers in the medical and health sciences. BMC Med Res Methodol 18:5. https://doi.org/10.1186/ s12874-017-0468-4

18. McGowan J, Sampson M, Salzwedel DM et al (2016) PRESS peer review of electronic search strategies: 2015 guideline statement. J Clin Epidemiol 75:40-46. https://doi.org/10.1016/j.jclinepi.2016. 01.021

19. Canadian Agency for drug and techonologies in Health (CADTH), Ottawa, Ontario, Canada. Grey matters: a practical tool for searching health-related grey literature. https://www.cadth.ca/resources/ finding-evidence/grey-matters. Accessed 10 Sep 2020

20. University of Bern, Switzerland. Systematic Searching - Grey literature. https://www.unibe.ch/universitaet/dienstleistungen/ universitaetsbibliothek/recherche/fachinformationen/medizin/ systematic_searching/where_to_search/grey_literature/index_ ger.html\#e688845. Accessed 10 Sep 2020

21. Kaunelis D, Farrah K, Severn M (2010) The Missing 2\%: PubMed NOT MEDLINE. https://www.cadth.ca/media/is/Search-dev/ Missing2_CHLA_ABSC_Poster.pdf. Accessed 10 Sep 2020

22. Munn Z, MClinSc SM, Lisy K, et al (2015) Methodological guidance for systematic reviews of observational epidemiological studies reporting prevalence and cumulative incidence data. Int J Evid Based Healthc 13:147-153. https://doi.org/10.1097/XEB.00000 00000000054

23. The Joanna Briggs Institute (JBI). Critical Appraisal Checklists. https://joannabriggs.org/critical-appraisal-tools. Accessed 11 Sep 2020

24. Barendregt JJ, Doi SA, Lee YY et al (2013) Meta-analysis of prevalence. J Epidemiol Community Health 67:974-978. https:// doi.org/10.1136/jech-2013-203104

25. MetaXL [Computer program]. Version 5.3, EpiGear, 2020.

26. Review Manager (RevMan) [Computer program]. Version 5.4, The Cochrane Collaboration, 2020.

27. Dhanuthai K, Rojanawatsirivej S, Thosaporn W et al (2017) Oral cancer: a multicenter study. Med Oral Patol Oral Cir Bucal 23(1):e23-29. https://doi.org/10.4317/medoral.21999

28. Buser D, Janner SFM, Wittneben J-G et al (2012) 10-year survival and success rates of 511 titanium implants with a sandblasted and acid-etched surface: a retrospective study in 303 partially edentulous patients. Clin Implant Dent Relat Res 14:839-851. https:// doi.org/10.1111/j.1708-8208.2012.00456.x

29. Smith Nobrega A, Santiago JF, de Faria Almeida DA et al (2016) Irradiated patients and survival rate of dental implants: 
a systematic review and meta-analysis. J Prosthet Dent 116:858866. https://doi.org/10.1016/j.prosdent.2016.04.025

30. Linsen S, Schmidt-Beer U, Fimmers R et al (2009) Craniomandibular pain, bite force, and oral health-related quality of life in patients with jaw resection. J Pain Symptom Manage 37:94-106. https://doi.org/10.1016/j.jpainsymman.2006.12.019

31. Visch LL, van Waas MAJ, Schmitz PIM, Levendag PC (2002) A clinical evaluation of implants in irradiated oral cancer patients. $\mathrm{J}$ Dent Res 81:856-859. https://doi.org/10.1177/154405910208101 212

32. Sammartino G, Marenzi G, Cioffi I et al (2011) Implant therapy in irradiated patients. J Craniofac Surg 22:443-445. https://doi. org/10.1097/SCS.0b013e318207b59b

33. Ettl T, Junold N, Zeman F et al (2020) Implant survival or implant success? Evaluation of implant-based prosthetic rehabilitation in head and neck cancer patients-a prospective observational study. Clin Oral Investig 24:3039-3047. https://doi.org/10.1007/ s00784-019-03172-9

34. Schiegnitz E, Al-Nawas B, Kämmerer PW, Grötz KA (2014) Oral rehabilitation with dental implants in irradiated patients: a meta-analysis on implant survival. Clin Oral Investig 18:687698. https://doi.org/10.1007/s00784-013-1134-9

35. Shugaa-Addin B, Al-Shamiri H, Al-Maweri S, Tarakji B (2016) The effect of radiotherapy on survival of dental implants in head and neck cancer patients. J Clin Exp Dent 8(2):e194-200. https://doi.org/10.4317/jced.52346

36. Alberga JM, Korfage A, Bonnema I et al (2020) Mandibular dental implant placement immediately after teeth removal in head and neck cancer patients. Support Care Cancer 28:59115918. https://doi.org/10.1007/s00520-020-05431-y

37. Schoen PJ, Raghoebar GM, Bouma J et al (2008) Prosthodontic rehabilitation of oral function in head-neck cancer patients with dental implants placed simultaneously during ablative tumour surgery: an assessment of treatment outcomes and quality of life. Int J Oral Maxillofac Surg 37:8-16. https://doi.org/10. 1016/j.ijom.2007.07.015

38. Claudy MP, Miguens SAQ, Celeste RK et al (2015) Time interval after radiotherapy and dental implant failure: systematic review of observational studies and meta-analysis. Clin Implant Dent Relat Res 17:402-411. https://doi.org/10.1111/cid.12096

39. Jegoux F, Malard O, Goyenvalle E et al (2010) Radiation effects on bone healing and reconstruction: interpretation of the literature. Oral Surgery, Oral Med Oral Pathol Oral Radiol Endodontology 109:173-184. https://doi.org/10.1016/j.tripleo.2009.10. 001

40. Johnsson ÅA, Sawaii T, Jacobson M et al (2000) A histomorphometric and biomechanical study of the effect of delayed titanium implant placement in irradiated rabbit bone. Clin Implant Dent Relat Res 2:42-49. https://doi.org/10.1111/j.1708-8208.2000. tb00105.x

41. Chrcanovic BR, Albrektsson T, Wennerberg A (2016) Dental implants in irradiated versus nonirradiated patients: a meta-analysis. Head Neck 38:448-481. https://doi.org/10.1002/hed.23875

42. Granström G (2006) Placement of dental implants in irradiated bone: the case for using hyperbaric oxygen. J Oral Maxillofac Surg 64:812-818. https://doi.org/10.1016/j.joms.2006.01.012

43. Eckert SE, Desjardins RP, Keller EE, Tolman DE (1996) Endosseous implants in an irradiated tissue bed. J Prosthet Dent 76:45-49. https://doi.org/10.1016/S0022-3913(96)90345-5

44. Chambrone L, Mandia J, Shibli JA et al (2013) Dental implants installed in irradiated jaws. J Dent Res 92:119S-130S. https://doi. org/10.1177/0022034513504947

45. Colella G, Cannavale R, Pentenero M, Gandolfo S (2007) Oral implants in radiated patients: a systematic review. Int J Oral Maxillofac Implants 22:616-622
46. Lee R, Estilo CL, Huryn JM et al (2012) Oropharyngeal cancer patients and mandibular dose distributions following intensity modulated radiation therapy. Int J Radiat Oncol 84:S481-S482. https://doi.org/10.1016/j.ijrobp.2012.07.1276

47. Landes CA, Kovacs AF (2006) Comparison of early telescope loading of non-submerged ITI implants in irradiated and non-irradiated oral cancer patients. Clin Oral Implants Res 17:367-374. https://doi.org/10.1111/j.1600-0501.2005.01227.x

48. Shah D, Chauhan C, Solanki J (2017) Effectiveness of hyperbaric oxygen therapy in irradiated maxillofacial dental implant patients: a systematic review with meta-analysis. J Indian Prosthodont Soc 17:109. https://doi.org/10.4103/0972-4052.203193

49. Esposito M, Worthington H V (2013) Interventions for replacing missing teeth: hyperbaric oxygen therapy for irradiated patients who require dental implants. Cochrane Database Syst Rev CD003603. https://doi.org/10.1002/14651858.CD003603.pub3

50. Shaw RJ, Butterworth CJ, Silcocks P et al (2019) HOPON (Hyperbaric Oxygen for the Prevention of Osteoradionecrosis): a randomised controlled trial of hyperbaric oxygen to prevent osteoradionecrosis of the irradiated mandible. Br J Oral Maxillofac Surg 57:e85. https://doi.org/10.1016/j.bjoms.2019.10.248

51. Moy PK, Medina D, Shetty V, Aghaloo TL (2005) Dental implant failure rates and associated risk factors. Int J Oral Maxillofac Implants 20:569-577

52. Kovács AF (2001) Influence of chemotherapy on endosteal implant survival and success in oral cancer patients. Int J Oral Maxillofac Surg 30:144-147. https://doi.org/10.1054/ijom.2000. 0023

53. Esposito M, Coulthard P, Oliver R et al (2003) Antibiotics to prevent complications following dental implant treatment. Cochrane Database Syst Rev CD004152. https://doi.org/10.1002/14651858. CD004152

54. Yerit KC, Posch M, Seemann M et al (2006) Implant survival in mandibles of irradiated oral cancer patients. Clin Oral Implants Res 17:337-344. https://doi.org/10.1111/j.1600-0501.2005. 01160.x

55. Reuther T, Schuster T, Mende U, Kübler A (2003) Osteoradionecrosis of the jaws as a side effect of radiotherapy of head and neck tumour patients - a report of a thirty year retrospective review. Int J Oral Maxillofac Surg 32:289-295. https://doi.org/10.1054/ijom. 2002.0332

56. Nabil S, Samman N (2011) Incidence and prevention of osteoradionecrosis after dental extraction in irradiated patients: a systematic review. Int J Oral Maxillofac Surg 40:229-243. https://doi. org/10.1016/j.ijom.2010.10.005

57. Wagner W, Esser E, Ostkamp K (1998) Osseointegration of dental implants in patients with and without radiotherapy. Acta Oncol 37:693-696. https://doi.org/10.1080/028418698430061

58. Keller E (1997) Placement of dental implants in the irradiated mandible: a protocol without adjunctive hyperbaric oxygen. J Oral Maxillofac Surg 55:972-980. https://doi.org/10.1016/S02782391(97)90073-2

59. Fenlon MR, Lyons A, Farrell S et al (2012) Factors affecting survival and usefulness of implants placed in vascularized free composite grafts used in post-head and neck cancer reconstruction. Clin Implant Dent Relat Res 14:266-272. https://doi.org/10. 1111/j.1708-8208.2009.00250.x

60. Nadella KR, Kodali RM, Guttikonda LK, Jonnalagadda A (2015) Osteoradionecrosis of the jaws: clinico-therapeutic management: a literature review and update. J Maxillofac Oral Surg 14:891-901. https://doi.org/10.1007/s12663-015-0762-9

61. Dumoulin S, van Maanen A, Magremanne M (2021) Dental prevention of maxillo-mandibular osteoradionecrosis: a ten-year retrospective study. J Stomatol Oral Maxillofac Surg 122:127-134. https://doi.org/10.1016/j.jormas.2020.05.022 
62. Owosho AA, Tsai CJ, Lee RS et al (2017) The prevalence and risk factors associated with osteoradionecrosis of the jaw in oral and oropharyngeal cancer patients treated with intensity-modulated radiation therapy (IMRT): The Memorial Sloan Kettering Cancer Center experience. Oral Oncol 64:44-51. https://doi.org/10. 1016/j.oraloncology.2016.11.015

63. Patel V, Gadiwalla Y, Sassoon I et al (2016) Prophylactic use of pentoxifylline and tocopherol in patients who require dental extractions after radiotherapy for cancer of the head and neck. Br J Oral Maxillofac Surg 54:547-550. https://doi.org/10.1016/j. bjoms.2016.02.024

64. Khadra M, Ronold HJ, Lyngstadaas SP et al (2004) Low-level laser therapy stimulates bone-implant interaction: an experimental study in rabbits. Clin Oral Implants Res 15:325-332. https://doi. org/10.1111/j.1600-0501.2004.00994.x

65. Pouremadi N, Motaghi A, Safdari R et al (2019) Clinical outcomes of low-level laser therapy in management of advanced implant surgery complications: a comparative clinical study. J Contemp Dent Pract 20:78-82. https://doi.org/10.5005/jp-journ als-10024-2479

66. de Oliveira GJPL, Aroni MAT, Pinotti FE et al (2020) Low-level laser therapy (LLLT) in sites grafted with osteoconductive bone substitutes improves osseointegration. Lasers Med Sci 35:1519-1529. https://doi.org/10.1007/s10103-019-02943-w

67. Ocaña RP, Rabelo GD, Sassi LM et al (2017) Implant osseointegration in irradiated bone: an experimental study. J Periodontal Res 52:505-511. https://doi.org/10.1111/jre.12416

68. Huang B, Yao Q, Huang Y et al (2018) Combination use of BMP2 and VEGF165 promotes osseointegration and stability of titanium implants in irradiated bone. Biomed Res Int 2018:1-11. https://doi. org/10.1155/2018/8139424

69. Liu H, Zhou W, Ren N et al (2017) Cell sheets of co-cultured endothelial progenitor cells and mesenchymal stromal cells promote osseointegration in irradiated rat bone. Sci Rep 7:3038. https://doi. org/10.1038/s41598-017-03366-9

70. Owosho AA, Kadempour A, Yom SK et al (2015) Radiographic osteoradionecrosis of the jaw with intact mucosa: proposal of clinical guidelines for early identification of this condition. Oral Oncol 51:e93-e96. https://doi.org/10.1016/j.oraloncology.2015.09.009

71. Rosen EB, Ahmed ZU, Randazzo JD et al (2020) Dental intervention for the irradiated patient: time to re-evaluate dental treatment algorithms? Br J Oral Maxillofac Surg 58:711-712. https://doi.org/ 10.1016/j.bjoms.2020.03.028

72. Korfage A, Schoen PJ, Raghoebar GM et al (2010) Benefits of dental implants installed during ablative tumour surgery in oral cancer patients: a prospective 5-year clinical trial. Clin Oral Implants Res 21:971-979. https://doi.org/10.1111/j.1600-0501.2010.01930.x

73. Hakim SG, Kimmerle H, Trenkle T et al (2015) Masticatory rehabilitation following upper and lower jaw reconstruction using vascularised free fibula flap and enossal implants-19 years of experience with a comprehensive concept. Clin Oral Investig 19:525-534. https://doi.org/10.1007/s00784-014-1247-9

74. Chiapasco M, Biglioli F, Autelitano L et al (2006) Clinical outcome of dental implants placed in fibula-free flaps used for the reconstruction of maxillo-mandibular defects following ablation for tumors or osteoradionecrosis. Clin Oral Implants Res 17:220-228. https://doi. org/10.1111/j.1600-0501.2005.01212.x

75. Smolka K, Kraehenbuehl M, Eggensperger N et al (2008) Fibula free flap reconstruction of the mandible in cancer patients: evaluation of a combined surgical and prosthodontic treatment concept. Oral Oncol 44:571-581. https://doi.org/10.1016/j.oraloncology.2007.07. 005

76. Iizuka T, Häfliger J, Seto I et al (2005) Oral rehabilitation after mandibular reconstruction using an osteocutaneous fibula free flap with endosseous implants. Clin Oral Implants Res 16:69-79. https://doi. org/10.1111/j.1600-0501.2004.01076.x
77. Rouers M, Bornert F, Truntzer P et al (2019) Ability to propose optimal prosthetic rehabilitation can be improved by discussion between the dentist and radiation oncologist regarding upstream dosimetry. Eur J Dent 13:088-094. https://doi.org/10.1055/s-0039-1688523

78. Bravata DM, Olkin I (2001) Simple pooling versus combining in meta-analysis. Eval Health Prof 24:218-230. https://doi.org/10. 1177/01632780122034885

79. Altman DG (2004) Pooling data is not meta-analysis. https://www. bmj.com/rapid-response/2011/10/30/pooling-data-not-meta-analy sis. Accessed 16 Sep 2020

80. Barber HD, Seckinger RJ, Hayden RE (1995) Reconstruction of the head and neck cancer patient with a vascularized fibula flap and dental implants: preliminary clinical report. Implant Dent 4:111-114

81. Franzén L, Rosenquist JB, Rosenquist KI, Gustafsson I (1995) Oral implant rehabilitation of patients with oral malignancies treated with radiotherapy and surgery without adjunctive hyperbaric oxygen. Int J Oral Maxillofac Implants 10:183-187

82. Watzinger F, Ewers R, Henninger A et al (1996) Endosteal implants in the irradiated lower jaw. J Cranio-Maxillofacial Surg 24:237-244. https://doi.org/10.1016/S1010-5182(96)80007-2

83. Weischer T, Schattler D, Mohr C (1996) Concept of surgical and implant-supported prostheses in the rehabilitation of patients with oral cancer. Int J Oral Maxillofac Implant 11:775-781

84. Keller EE, Tolman DE, Zuck SL, Eckert SE (1997) Mandibular endosseous implants and autogenous bone grafting in irradiated tissue: a 10-year retrospective study. Int J Oral Maxillofac Implants 12:800-813

85. Weischer T, Mohr C (1997) Early detection of threatened implant loss in tumor patients. Mund-, Kiefer- und Gesichtschirurgie MKG 1:294-299

86. Andersson G, Andreasson L, Bjelkengren G (1998) Oral implant rehabilitation in irradiated patients without adjunctive hyperbaric oxygen. Int J Oral Maxillofac Implants 13:647-654

87. August M, Bast B, Jackson M, Perrott D (1998) Use of the fixed mandibular implant in oral cancer patients: a retrospective study. J Oral Maxillofac Surg 56:297-301. https://doi.org/10.1016/S02782391(98)90102-1

88. Brogniez V, Lejuste P, Pecheur A, Reychler H (1998) Dental prosthetic reconstruction of osseointegrated implants placed in irradiated bone. Int J Oral Maxillofac Implants 13:506-512

89. Keller EE, Tolman D, Eckert S (1998) Endosseous implant and autogenous bone graft reconstruction of mandibular discontinuity: a 12-year longitudinal study of 31 patients. Int J Oral Maxillofac Implants 13:767-780

90. Esser E, Neukirchen S, Wagner W (1999) Vergleichende Untersuchungen von Brånemark-Implantaten im bestrahlten und nicht bestrahlten Unterkiefer. Mund-, Kiefer- und Gesichtschirurgie 3:S125-S129. https://doi.org/10.1007/PL00014498

91. Schoen PJ, Raghoebar GM, Vissink A, Roodenburg JLN (2003) Mandibulotomy and implant insertion. Head Neck 25:748-753. https://doi.org/10.1002/hed.10284

92. Shaw RJ, Sutton AF, Cawood JI et al (2005) Oral rehabilitation after treatment for head and neck malignancy. Head Neck 27:459-470. https://doi.org/10.1002/hed.20176

93. Bodard AG, Gourmet R, Lucas R et al (2006) Implants dentaires en territoire irradié. Rev Stomatol Chir Maxillofac 107:137-142. https://doi.org/10.1016/S0035-1768(06)77007-3

94. Schoen PJ, Raghoebar GM, Bouma J et al (2007) Rehabilitation of oral function in head and neck cancer patients after radiotherapy with implant-retained dentures: effects of hyperbaric oxygen therapy. Oral Oncol 43:379-388. https://doi.org/10.1016/j.oraloncolo gy.2006.04.009

95. Liberali S (2009) Implant rehabilitation of the edentulous irradiated mandible. Thesis (D.Clin.Dent.), School of Dentistry, University of Adelaide 
96. Linsen SS, Martini M, Stark H (2012) Long-term results of endosteal implants following radical oral cancer surgery with and without adjuvant radiation therapy. Clin Implant Dent Relat Res 14:250-258. https://doi.org/10.1111/j.1708-8208.2009.00248.x

97. Curi MM, Condezo AFB, Ribeiro KDCB, Cardoso CL (2018) Longterm success of dental implants in patients with head and neck cancer after radiation therapy. Int J Oral Maxillofac Surg 47:783-788. https://doi.org/10.1016/j.ijom.2018.01.012

98. Desoutter A, Deneuve S, Condamin S-C, Chaux-Bodard A-G (2018) Long-term implant failure in patients treated for oral cancer by external radiotherapy: a retrospective monocentric study. J Oral Med Oral Surg 24:103-106. https://doi.org/10.1051/mbcb/2017041
99. Takahashi D, Suzuki H, Komori T (2018) A clinical study of 103 dental implants in oral cancer patients after jaw resection. J Oral Maxillofac Surgery, Med Pathol 30:206-211. https://doi.org/10. 1016/j.ajoms.2017.12.006

Publisher's note Springer Nature remains neutral with regard to jurisdictional claims in published maps and institutional affiliations. 